\title{
An Evaluation for the Use of Blockchain Technology in Logistics
}

\author{
Alexander Goudz, Valentino Steiner \\ Transport \& Logistics, University Duisburg-Essen, Duisburg, Germany \\ Email address: \\ alexander.goudz $a$ uni-due.de (A. Goudz), valentino.steiner $a$ stud.uni-due.de (V. Steiner)

\section{To cite this article:} \\ Alexander Goudz, Valentino Steiner. An Evaluation for the Use of Blockchain Technology in Logistics. International Journal of \\ Transportation Engineering and Technology. Vol. 5, No. 1, 2019, pp. 11-17. doi: 10.11648/j.ijtet.20190501.12
}

Received: February 22, 2019; Accepted: April 4, 2019; Published: May 10, 2019

\begin{abstract}
The following article sums up the current problems of the logistics and explains how the Blockchain technology can help to solve some of them. A utility value analysis is used to quantify the scenarios the Blockchain is most likely to be used in. This offers a result that, in comparison to current research, does not only show the opportunities but also how likely they are to be used in these sections. In the next step these scenarios are compared with each other. These results lead to a outlook to potential applications of the Blockchain technology in the logistics.
\end{abstract}

Keywords: Blockchain, Utility Value Analysis, Potential Applications, Scenarios, Smart Contract, Cloud, IOT

\section{Introduction}

The supply chains have undergone big changes in recent years. [1] The effect of this are new problems logistics has to face. These challenges require a different strategy and new technologies because the current design is unable to handle the demands. The changes are therefore necessary to face the rising complexity of the processes. [2]

What are the current problems logistics has to face?

Supply chains and logistics are at their limits. The complexity has risen massively due to an increase in the number of actors involved and the emergence of new external factors. [3] The rising cost pressure is an external force that leads to companies sourcing out their logistics and keeping only a low buffer in the warehouse. [4] An effect of this is a lack of transparency both companies and customers suffer from. [5] All of the challenges require a higher standard of digitalization, in other words there is a need for software solutions. The so-called Logistics 4.0 tries to solve the mentioned problems but is still at early stage. [6] The Blockchain technology can potentially take a major role in this development.

What is Blockchain?

Although no commonly accepted definition has been established yet, Blockchain can be characterized as a peer-to-peer distributed ledger without any doubt. [7] In practical application, Blockchain is used as a database platform to exchange values in a secure way. [8] The overall term is used to describe "distributed account management systems with which common data can be used across several digital locations"[9] or, in short, the "principle of a distributed general ledger with transaction accounts". [10] The transactions in a block chain run through a system of keys, using both public and private keys. The transaction is followed by verification. This takes place with the underlying idea that a transaction must be checked according to agreed regulations before it can be stored in the Blockchain. [11]

Once verification is complete, the next step is block formation. To do this, several verified transactions are bundled to form a block. Checksums, so-called hash values, are then created for these blocks. To do this, copies of the transactions are first encrypted individually and then in pairs until a single hash value remains.

To achieve an automatic consensus between all nodes, the Blockchain technology uses the proofing process. The difficulty in finding a consensus is known as the problem of the Byzantine generals, which is the situation that arises when different parties do not trust each other but must have a communication mechanism with each other. [12] Then the distribution takes place. The Blockchain is copied to all computers in the network. All members thus have a local copy, which is updated with each new block. [13]

One result is that the $\mathrm{BC}$ technology is a combination of different elements, some of which have already been known 
(cryptography), but within Blockchain they serve a new purpose (hash function).

\section{Current State of Science}

After Bitcoin has become more and more popular researchers started to focus on the Blockchain, the technology behind it, too. The hype about the topic arose around 2015, when many articles were published in non-scientific journals. As a result, the management consultants Gartner currently lists the Blockchain technology in exaggerated expectations and on the way to disappointment or disillusionment. [14] The articles cover the topics of use-cases of the Blockchain technology, technical description of the Blockchain technology, SWOT-analysis, and general potential of the Blockchain technology. They discuss the theoretical implementation without, however, quantifying it. In the field of logistics, however, the research and application of Blockchain is still in its infancy. [13] In addition, the topic has rarely been covered comprehensively so far. [7]

\section{Materials and Methods}

To close the gap this paper quantifies the findings from research literature. The aim of the evaluation is to generate comparable values that can be put in relation to each other. To achieve this, the utility value analysis is to be used which is characterized by good traceability and transparency. [15]

A scale of 1-5 will be used to assess the degree of fulfilment, with 1 being the lowest value and 5 the highest. The scale was chosen because it has the advantage that two numbers represent a high (4.5) or low (1.2) and one (3) a neutral degree of fulfillment. The weighting is subdivided into three relevancies. Low and high relevance thus have an influence on the degree of fulfillment, whereas normal relevance does not change the value. Together with the differently weighted ratings, see Table 1 , a maximum of 32.5 points can be achieved.

The complexity of the design refers to the technological structure of a Blockchain. A high level of complexity could lead to companies being deterred from using Blockchain technology. This criterion has a normal relevance and is therefore weighted with a factor of 1 .

The fulfilment of customer needs is an even more important factor and for the companies, since by content customers a better customer connection. That is why this criterion is assigned a factor of 1.5.

The term "degree of acceptance" refers to the acceptance by the companies. The acceptance is however seen as less relevant than the customer needs and therefore provided with the factor 1 .

Under "costs", both the entrance and the subsequent costs and the potential cost savings are to be summarized. Since the reduction of costs can be one of the main incentives for an implementation of the $\mathrm{BC}$ technology by enterprises, costs are assigned the factor 1.5.

The "duration of an implementation" depends on the acceptance, the available resources and the complexity of the design. For companies, the duration has a high relevance because the daily business can suffer. It is therefore weighted by a factor of 1.5 .

Table 1. Criteria to be examined. Source: own research.

\begin{tabular}{lll}
\hline Criterion & weighting & degree of fulfillment \\
\hline Complexity & 1 & 4 \\
customer requirements & 1.5 & 4 \\
Acceptance & 1 & 4 \\
Costs & 1.5 & 2 \\
Duration of implementation & 1.5 & 3 \\
implementation probability & - & - \\
\hline
\end{tabular}

Vertical lines are optional in tables. Statements that serve as captions for the entire table do not need footnote letters.

${ }^{\mathrm{a}}$ Gaussian units are the same as cg emu for magnetostatics; $\mathrm{Mx}=$ maxwell, $\mathrm{G}=$ gauss, $\mathrm{Oe}=$ oersted; $\mathrm{Wb}=$ weber, $\mathrm{V}=\mathrm{volt}, \mathrm{s}=\mathrm{second}, \mathrm{T}=$ tesla, $\mathrm{m}=$ meter, $\mathrm{A}=$ ampere, $\mathrm{J}=$ joule, $\mathrm{kg}=$ kilogram, $\mathrm{H}=$ henry.

\section{Results}

According to Burgwinkel [16], there are four application forms of Blockchain technology in practice: First, Blockchain software that provides the program code to perform the cryptographic procedures. A second application are the Blockchain platforms, which use selected software and are operated on the Internet as a service, e.g. as an open peer-to-peer network or as a commercial service. The third application variant are Blockchain applications for the realization of a specific application. Typically, these applications are operated with the help of Blockchain software or on a Blockchain platform. Finally, the fourth application is a Blockchain-as-a-Service, which provides the necessary software and services in a cloud. [16]
Decentralization of the network is the first change using BC technology. An implementation of the Blockchain technology has a direct impact on the running process, although it remains practically unchanged. [17] The conversion into decentralized systems, however, causes disturbances in the operation process at least at the local level. [18]

The digitalization of the network is also a measurable change. The automation that goes along with the digitalization of the processes has several effects. Thus, a reduction in errors can be observed, both in the transmission of information and during transport. In addition, the transmission speed is increased, which leads to an increase in efficiency. [19]

The use of Blockchain technology greatly reduces the risk of system failure. [20] This tackles the vulnerability problem of the supply chain. 
The increased transparency a Blockchain application brings with it means that any authorized user can see at any time where a product or information comes from and what the ownership structure looks like. [21] This can satisfy the customer's need for complete transparency, as described above. Indirectly, the logistics department also detects the consequences by reducing the pressure to show the complete transport chain.

The Blockchain technology offers the possibility of cost reduction for various reasons. The costs for transactions can drop rapidly with a mass use, for example by the omission of an intermediary. [22] By standardizing or automating transactions, they can also be carried out in a shorter time. A further cost reduction is to be found in savings on security costs. [17]

Equal involvement of all parties in the network is another change that makes cooperation possible. A fair distribution of information also enables smaller companies to act at eye level with the Blockchain. [19]

Above all, the pressure to work together more intensively can be managed well with a Blockchain in the logistics industry with its large number of companies, since trust is created to share data with each other and everyone has access to all shared information. The increased transparency associated with the Blockchain technology enables this function. The fact that the ownership structure is clearly recognizable reduces the risk of an interaction with other parties. [19]

On Blockchain technology, Bachmann et al. [23] writes that the potential magnitude of the changes and their consequences for companies is much more substantial than it was with previous technologies. Basically, logistics players and companies agree that there will be positive effects. [24]

A current hurdle is the lack of standards, which means to agree on a common model. This also includes legal concerns that may prevent companies from using $\mathrm{BC}$ technology due to a lack of precedent. [21] In addition, data protection, which is subject to clear guidelines such as the right to deletion, is also an issue.

The lack of a central authority and thus of an organization that takes over the leadership and sets goals can also be described as a hurdle in the moment.

From a technical point of view, there are two additional hurdles for Blockchain use. For both, this is only a snapshot of the state of the art. So far, no high scalability can be offered, which limits the application possibilities of BC technology in logistics. The transaction speed also ensures that many processes are extended over time. [11]

There is currently a large discrepancy between the hype and large-scale applications. Obvious parallels can be drawn here with cloud technology, where short-term applications were also rare at the beginning due to security concerns and a high degree of complexity. [23]

Since the technological development of BC is still in its early stages, parts of the research tend to say that its potential has only been reached to a limited extent. [9]

From the current status three application scenarios can be derived, which will be presented in the following.

\section{Scenario 1: Smart Contract}

The Blockchain technology can be used to create a smart contract that runs autonomous. This form of implementation is already in use. [25]

The smart contract function makes the process more efficient by digitalizing it in the first place. Furthermore, there is a cost cut for putting together contracts and executing them, because it takes less time. [26]

Complexity

The basic architecture of a Smart Contract is not very complex. However, the infrastructure behind it such as the automation of contracts and safeguarding, must also be established, which significantly increases the complexity.

Customer requirements

A Smart Contract can ensure the automatic execution of a fixed program that offers the customer more security than a paper contract. In addition, customer requests for information will be implemented in real time and access rights will become more transparent. Overall, from the customer's point of view, Smart Contracts can be used to negotiate at the same level as the companies.

Acceptance

The acceptance of Smart Contracts depends above all on the legal protection. The acceptance of decentralized storage is also important. In Germany, this is a difficult topic due to the high data protection requirements, so the degree of acceptance can be rated as relatively low.

Costs

The costs must be divided into implementation costs and process costs. It is difficult to find figures for the changeover costs, because they accompany the entire process of digitizing documents. However, it can be assumed that the transformation will affect day-to-day operations as well as personnel and training costs.

Duration of an implementation

The time required for the changeover is relatively high. Many processes have to be digitized, the Smart Contracts and their conditions have to be partially rewritten and the employees have to be trained.

Table 2. Evaluation of the implementation probability of the Blockchain technology in scenario 1. Source: own research.

\begin{tabular}{llll}
\hline Criterion & Weighting & Degree of fulfillment & Score \\
\hline Complexity & 1 & 4 & $4 / 5$ \\
customer requirements & 1.5 & 4 & $6 / 7.5$ \\
Acceptance & 1 & 2 & $2 / 5$ \\
Costs & 1.5 & 3 & $6 / 7.5$ \\
Duration of an implementation & 1.5 & 3 & $4.5 / 7.5$ \\
implementation probability & - & - & $22.5 / 32.5$ \\
\hline
\end{tabular}




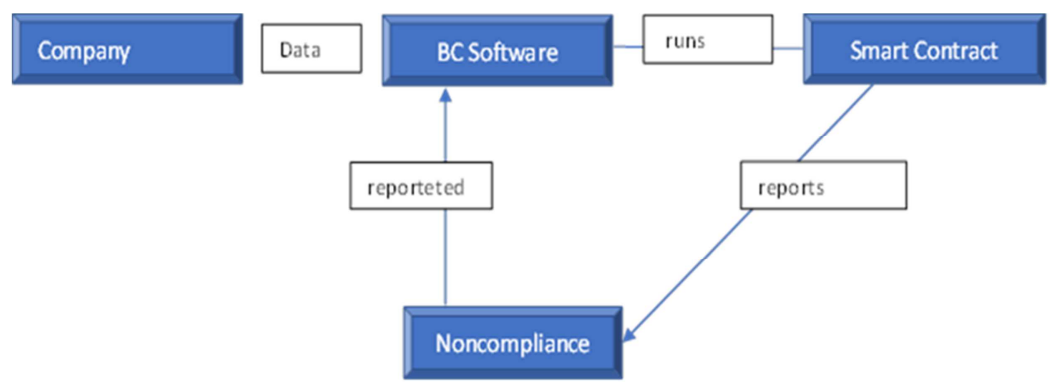

Figure 1. Scenario of a Smart-Contract. Source: own research.

Figure 1 shows a design of the scenario that is simply structured: a company uses a Blockchain software that runs a Smart Contract.

Overall, this use case scenario is suggested to smaller companies that are not able to take a financial risk but on the other hand see the necessity to digitalize their processes.

As the application has already been tested in practice, this reduces the risk of failure of the implementation for the companies. In addition, the use of a Smart Contract has short-term effects, which are caused by automation.

The strengths of the design of scenario 1 are outsourcing the data to an external platform and the associated increase in efficiency, as well as the simple structure, which ensures that the implementation can easily be overlooked. A weakness is the interruption of the ongoing process and the associated increased risk of a system failure in the event of a changeover.

Scenario 2: Blockchain and Cloud technology

While the Cloud technology is already being used by a large amount of companies there are still challenges that have to be faced to reach its full potential. Some companies still have trust issues about the sensitive data that is kept centralized on the cloud and could easily be hacked. [27]

The Blockchain technology offers two solutions for this problem: the decentralization of the cloud and the protection of the data. The decentralization goes along with the trend to distribute the information and resources in order to be more efficient and to lower the risk of losing them. The Blockchain fits perfectly to the cloud by adding value to its current technology. This scenario is not yet in use. The current state of the $\mathrm{BC}$ technology makes the cloud run slower by being in a bottleneck situation. Nevertheless, it is an interesting use case for companies, which do not use all the functions of the cloud because they are too skeptical about the security issues.

Complexity

The Blockchain technology is integrated into the existing cloud design. This increases the complexity, but the $\mathrm{BC}$ can run parallel to the cloud application without disrupting the process.

Customer requirements

In addition to the technical advantages such as faster data transfer and larger storage space, the author believes that the customer requirements for a cloud are above all the guarantee of higher data protection. This wish for security can be better guaranteed by using BC in the cloud, because BC operates decentrally and thus prevents data loss.

Acceptance

Acceptance mainly depends on the skepticism about data loss discussed in the previous section. According to the author, the use of BC technology can lower this skepticism and thus lower the inhibition threshold of a cloud application for companies.

Costs

The costs of an implementation are difficult to estimate, but a reducing factor is that the existing cloud process does not need to be interrupted to integrate the Blockchain. This eliminates the additional cost of stopping the process. The impact of a combination of the two technologies on usage costs still needs to be investigated, but there is a tendency for $\mathrm{BC}$ technology to slow down and thus become more expensive to use due to technological hurdles it still must overcome. From today's point of view, Blockchain seems to have the potential to reduce costs in this scenario.

Duration of an implementation

The duration of the implementation can be considered as short due to the parallel use without interruption (in the opinion of the author). However, the follow-up costs of a changeover must also be considered. Since the function of the $\mathrm{BC}$ in the cloud comes close to a database used for checking and backup, the BC runs in the background and, in the author's opinion, does not require much time afterwards apart from the link at the beginning.

Table 3. Evaluation of the implementation probability of the Blockchain technology in scenario 2 Source: own research.

\begin{tabular}{llll}
\hline Criterion & Weighting & degree of fulfillment & Score \\
\hline Complexity & 1 & 4 & $4 / 5$ \\
customer requirements & 1.5 & 4 & $6 / 7.5$ \\
Acceptance & 1 & 2 & $2 / 5$ \\
Costs & 1.5 & 3 & $3 / 7.5$ \\
Duration of an implementation & 1.5 & 3 & $4.5 / 7.5$ \\
implementation probability & - & - & $19.5 / 32.5$ \\
\hline
\end{tabular}

The design of the second use case is more complex than that of the first and, unlike the latter, runs tasks parallel.
One strength of the scenario 2 is its parallel application, which does not influence the running process, making an 
implementation more attractive for companies.

On the other hand, the weakness of the design is that the process is much more complex than in the first scenario. The Blockchain potentially slows down the performance of the cloud because the duration of processes is significantly increased by testing.

Thus, the Blockchain is used as a database, so that all transactions are still traceable and unchangeable and the flow of data in the cloud is not restricted.

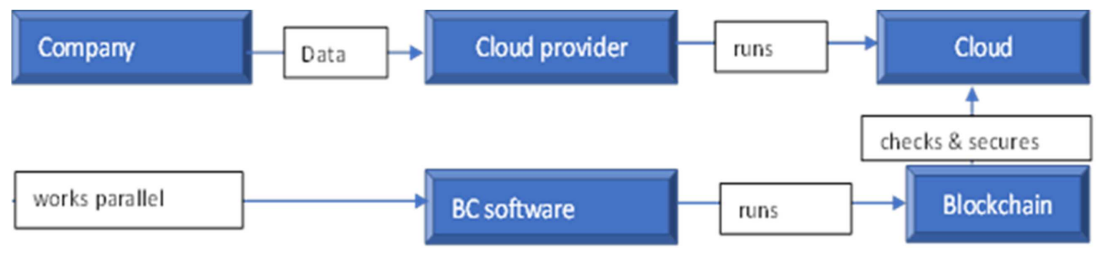

Figure 2. Scenario of a use of BC in the Cloud. Source: own research.

\section{Scenario 3: Blockchain and IOT technology}

Internet of Things (IOT) has a very high potential to change logistics. Although the research about this topic is still quite speculative, the challenges that this technology has to face seem quite clear: guarantee the user full control and protection against hacker. [28]

That's where the Blockchain technology comes into play. By securing the process, it helps building a reliable image. The $\mathrm{BC}$ technology should be used in the background or as a backup. Because of the status of the IOT, the Blockchain technology can be established permanently in the IOT technology of the future.

Complexity

The main task of the Blockchain technology in this application scenario is safeguarding. Although the basic design can resemble a smart contract, the author believes that the complexity is likely to be significantly higher.

Costumer requirements

This criterion is difficult to evaluate at this stage. From the author's point of view, the question arises whether there already are customer demands for the IOT technology. In its intended role as a secure platform, Blockchain technology seems to be able to meet customer requirements precisely because it cannot be changed.

Acceptance

Since the Internet of Things itself is a future technology and must first achieve the acceptance of the public and the companies itself, an assessment is difficult. Assuming that the acceptance is generated independently from the IOT technology, the statement can be made that the acceptance for the securing function of the $\mathrm{BC}$ is high.

Costs

The costs of an implementation are difficult to determine. The same applies to its savings potential. The investment costs are high because all devices must first be equipped with a sensor. The infrastructure is complex too and therefore expensive. It can also be assumed that costs will decrease with the number of networked devices. However, compared to security issues cost reduction does not have priority here.

Duration of an implementation

It is not possible to make a categorical statement about the duration of the implementation because it depends on the number of connected devices. Nevertheless, it can be stated that this can take place without stopping the network, which reduces the duration.

Table 4. Evaluation of the implementation probability of the Blockchain technology in scenario 3. Source: own research.

\begin{tabular}{|c|c|c|c|}
\hline Criterion & Weighting & degree of fulfillment & Score \\
\hline Complexity & 1 & 4 & $2 / 5$ \\
\hline customer requirements & 1.5 & 4 & $4.5 / 7.5$ \\
\hline Acceptance & 1 & 2 & $4 / 5$ \\
\hline Costs & 1.5 & 3 & $4.5 / 7.5$ \\
\hline Duration of an implementation & 1.5 & 3 & $6 / 7.5$ \\
\hline implementation probability & - & - & $21 / 32.5$ \\
\hline
\end{tabular}

This third scenario (Figure 3) also has the possibility to implement a parallel application of the Blockchain and the IOT devices.

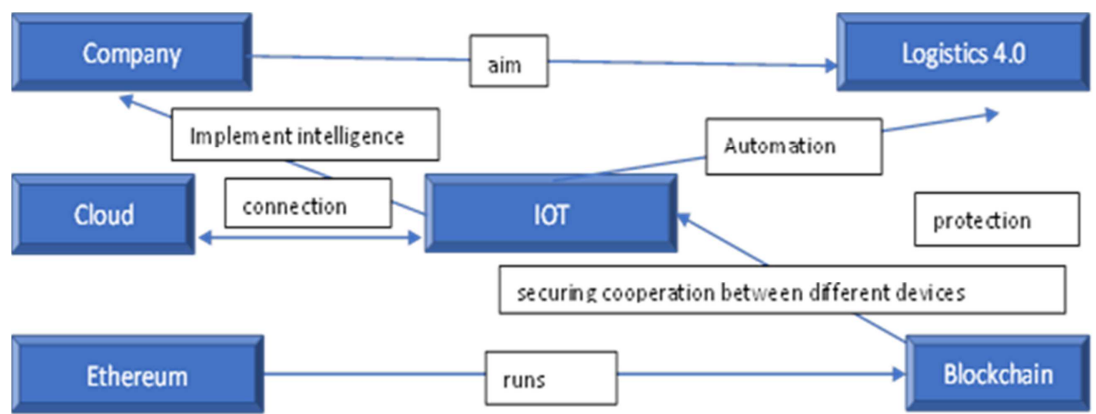

Figure 3. Scenario of a use of BC in IOT. Source: own research. 
A strength of the design of Scenario 3 are the applications through the Blockchain that run in the background of the complex processes. There is still a lot of research and projects ahead of the combined use, which is why I suggest large companies who are able to spend money in a possible failure to invest in this scenario. It is important to follow up on the latest trends and technologies in order to keep track with your competitors.

Of the three scenarios, the first has the highest score, wherefore it can be concluded that the probability of implementation is highest. The scenario of an implementation of the Blockchain Technology into an IOT structure follows with a distance of 1.5 points. From this it can be concluded that an implementation is generally more difficult to realize, which is related to the still unclear structure and success of IOT systems.

The scenario of an implementation in the cloud is the worst in comparison. Nevertheless, it is still interesting for the future because Blockchain technology has clear advantages over existing technology.

\section{Potential Applications of Blockchain Technology in Logistics}

\section{Tracking \& Tracing}

With Tracking \& Tracing, each product is given a unique code after manufacture, which is passed on manually when an order is started. This process is also well-established for tracking products during transport.

However, using the current approach of tracking and tracing, there is the problem of losing manually forwarded information and the lack of transparency in global shipments. [29]

The use of Blockchain technology simplifies the distribution of information, which is automated and can be carried out and tracked in real time via the Internet. [13]

For practical implementation, a transponder is used which is enclosed with the goods and through which the consignment can be identified. [4]

This deployment scenario is expected to have a major positive effect on transport logistics in particular. The maritime industry, for example, is hoping for cost reductions and an increase in trade volume of up to 15 percent. [30]

\section{Guarantee of origin}

In addition to a tracking and tracing function, which maps a supply chain to the front in real time, a retrograde proof of origin can also be implemented via a Blockchain. The problem using the current methods consists in the fact that the origin of a product is not always clearly visible. [21]

The potential of implementing Blockchain technology lies in the possibility of making it visible and authentic. [31] To achieve this, the Blockchain compares whether the location where the goods were last registered matches the agreed location in the freight bill used for identification. [3]

In addition, the authenticity of products can be checked to prevent counterfeiting. [32]

\section{Conclusions}

One finding is that, in addition to new technologies, a decentralized infrastructure is also necessary to implement the change in logistics, because the central structure leads to limitations in growth and computing power. [33]

The most important finding of this investigation of the $\mathrm{BC}$ is that this technology, at least in theory, can address and solve the problems of the logistics industry to a large extent.

The best results of the utility analysis to determine the degree of fulfilment by BC can be seen in the following areas: creating transparency, reducing complexity, facilitating the handling of customer needs and creating a common platform for all actors.

The probability of a successful implementation of $\mathrm{BC}$ technology is high in small companies, especially when using Smart Contracts. Despite the lack of parallel application in the transition and the associated interruption of the process, the improvements are so high that a deployment can be tackled without great financial risk. BC's collaboration with IOT and Cloud is more likely to result in large to mid-sized companies as a further outcome.

However, a general finding is that the likelihood varies from case to case, so separate research is needed. If you want to look at the future, there are three possibilities in which direction $\mathrm{BC}$ technology will develop: replacement of other business models, disappearance or use as niche technology.

\section{References}

[1] Crandall R; Crandall, W.; Chen, C. Principles of supply chain management, CRC Press Taylor \& Francis Group: Boca Raton, Florida, USA, 2010, pp. 509-518.

[2] Gallay, O.; Korpela, K.; Tapio, N.; Nurminen, J. A peer-to-peer platform for decentralized logistics. In Digitalization in supply chain management and logistics. Smart and Digital Solutions for an Industry 4.0 Environment. Proceedings of the Hamburg International Conference of Logistics (HICL) 23, Hamburg, Germany, 2017; Blecker, T., Ringle, C.; Kersten, W.; epubli GmbH: Berlin, Germany, 2017; p. 20.

[3] Matzer, M. Sicherheit für die Lieferkette. VDI Nachrichten 2017, 19, p. 25.

[4] Hackius, N.; Petersen, M.; See, B. Mapping the Sea of Opportunities: Blockchain in Supply Chain and Logistics, 2017 , p. $628 . \quad$ Available online: https://www.researchgate.net/publication/320353682_Mappin $\mathrm{g}$ the_Sea_of_Opportunities_Blockchain_in_Supply_Chain_a nd Logistics? $\bar{c}$ channel $=$ doi\&linkId $=59 \mathrm{df} 9 \overline{2} 5 \overline{70 \mathrm{f}} 7 \mathrm{e} 9 \mathrm{~b} 2 \mathrm{dba} 83 \overline{9}$ $7 \mathrm{~b} \&$ showFulltext=true.

[5] Amr, M.; Eljazzar, M.; Ezzat, M.; Kassem, M. Merging supply chain and Blockchain technologies. In THE INTERNATIONAL MARITIME TRANSPORT \& LOGISTICS CONFERENCE, MARLOG 7, Alexandria, Egypt, 2018; pp. 1-7. 
[6] Bousonville, T. Logistik 4.0. Die digitale Transformation der Wertschöpfungskette; Springer Fachmedien: Wiesbaden, Germany, 2017; p. 5.

[7] Fridgen, G.; Schlatt, V.; Schweizer, A.; Urbach, N. Blockchain Grundlagen, Anwendungen und Potenziale. White Paper, Projektgruppe Wirtschaftsinformatik des Fraunhofer-Instituts für Angewandte Informationstechnik FIT 2016, p. 7.

[8] Bashir, I. Mastering Blockchain. Distributed ledgers, decentralization and smart contracts explained; Packt: Birmingham, UK, 2017; p. 17.

[9] Brühl, V. Bitcoins, Blockchain und Distributed Ledger. Wirtschaftsdienst 2017, 97, no. 2, pp. 140-141.

[10] Brühl, V. Bitcoins, Blockchain und Distributed Ledger. Wirtschaftsdienst 2017, 97, no. 2, p. 135.

[11] Hackius, N.; Kersten, W.; Petersen, M. Blockchains für Produktion und Logistik. Grundlagen, Potenziale und Anwendungsfälle. ZWF Zeitschrift für wirtschaftlichen Fabrikbetrieb 2016, 111, no. 10; pp. 627-629.

[12] Swan, M. Blockchain: blueprint for a new economy; O'Reilly: Beijing, China, 2015; p. 2.

[13] Hackius, N.; Petersen, M. Blockchain in logistics and supply chain. Trick or treat?. In Proceedings of the Hamburg International Conference of Logistics (HICL) 23, Hamburg, Germany, 2017; Blecker, T; Ringle, C.; Kersten, W. Digitalization in supply chain management and logistics. Smart and Digital Solutions for an Industry 4.0 Environment, epubli GmbH: Berlin, 2017; pp. 4-5.

[14] Gartner Inc. Gartner Hype Cycle for Emerging Technologies. Available online: https://blogs.gartner.com/smarterwithgartner/files/2017/08/Em erging-Technology-Hype-Cycle-for-2017_Infographic_R6A.j pg.

[15] Bremer, P.; Brüggemann H., Grundlagen Qualitätsmanagement. Von den Werkzeugen über Methoden zum TQM, 2nd ed., Springer Vieweg: Wiesbaden, Germany, $2015 ;$ p. 26

[16] Burgwinkel, D. Blockchain Technology. Einführung für Business- und IT Manager. De Gruyter Oldenbourg: Berlin, Germany, 2016; p. 5.

[17] Thomas, D. Blockchain as a Backbone to Asset and Wealth Creation. In Barberis, J.; Chishti, S. The wealthtech book. The investment technology handbook for money managers, entrepreneurs and change-makers; Hoboken: Wiley, 2018, pp. $170-172$.

[18] Jahn, M. Industrie 4.0 konkret. Ein Wegweiser in die Praxis, Springer Gabler: Wiesbaden, Germany, 2017; p. 5.

[19] Domberg, C.; Eggers, L.; Großkopf Nehls, S.; Grotemeier, C.; Koß, D.; Posanok, N.;, Welina, A. Eins Zwei Drei Vier, 3, 2018 , p. 7 .
[20] Fridgen, G.; Schlatt, V.; Schweizer, A.; Urbach, N. Blockchain Grundlagen, Anwendungen und Potenziale. White Paper, Projektgruppe Wirtschaftsinformatik des Fraunhofer-Instituts für Angewandte Informationstechnik FIT 2016, p. 37.

[21] DHL Trend Research, 4. DHL Trend Research Blockchain in Logistics, Perspectives on the upcoming impact of Blockchain technology and use cases for the logistics industry, 2018, pp. 4-5. Available online: https://www.logistics.dhl/content/dam/dhl/global/core/docume nts/pdf/glo-core-Blockchain-trend-report.pdf.

[22] Bashir, I. Mastering Blockchain. Distributed ledgers, decentralization and smart contracts explained; Packt: Birmingham, UK, 2017; p. 31.

[23] Bachmann, A.; Grossi, M.; Hediger, T.; Seffinga, J. Blockchain in der Praxis. Expert Focus 2017, 91, pp. 811-812.

[24] Partida, B. Blockchain's great potential. Supply Chain Management Review 2018, 22, no. 1, p. 51.

[25] Gayvoronskaya, T.; Meinel, C.; Schnjakin, M. Blockchain. Hype oder Innovation. Technische Berichte des Hasso-Plattner-Instituts für Softwaresystemtechnik an der Universität Potsdam 2018, 113, p. 32.

[26] Sprenger, P. Blockchain meets Supply Chain. Logistik entdecken 2018, 18, p. 22.

[27] Gayvoronskaya, T.; Meinel, C.; Schnjakin, M. Blockchain. Hype oder Innovation. Technische Berichte des Hasso-Plattner-Instituts für Softwaresystemtechnik an der Universität Potsdam 2018, 113, p. 75.

[28] Demartini, C.; Lamberti, F.; Gatteschi, V.; Pranteda, C; Santamaria, V. To Blockchain or Not to Blockchain: That Is the Question. IT Professional 2018, 20, no. 2, p. 67.

[29] Knüpffer, G. Blockchain: So wird die Supply Chain transparent Produktion 2018, 7, pp. 4-5.

[30] Bottler, S.; Semmann, C. Blockchain hält Einzug in der Supply Chain.. DVZ Verkehrs-Zeitung 2017, 56, p. 5.

[31] Brenig, C.; Müller, G.; Rückeshäuser, N. Blockchains als Grundlage digitaler Geschäftsmodelle. Datenschutz und Datensicherheit 2017, 41, no. 8, p. 492.

[32] DHL Trend Research, 4. DHL Trend Research Blockchain in Logistics, Perspectives on the upcoming impact of Blockchain technology and use cases for the logistics industry, 2018, p. 15. Available online: https://www.logistics.dhl/content/dam/dhl/global/core/docume nts/pdf/glo-core-Blockchain-trend-report.pdf.

[33] Bauernhansl, T.; Hompel, M.; Vogel-Heuser, B., Industrie 4.0 in Produktion, Automatisierung und Logistik: Anwendung. Technologien. Migration. Springer Fachmedien: Wiesbaden, Germany, 2014, p. 15. 